\title{
Foreign Direct Investment and Technology Transfer: Knowledge Spillover in the Manufacturing Sector in Indonesia
}

Global Business Review I8(I) 57-70

(C) 2017 IMI

SAGE Publications sagepub.in/home.nav DOI: I0.I I77/0972| 509|6666878 http://gbr.sagepub.com

\section{Horas Djulius'}

\begin{abstract}
Knowledge spillover, as a form of technology transfer from foreign direct investment (FDI), has frequently been investigated in the contexts of various countries. This study aims to examine whether the availability of labour working for foreign companies could trigger improved productivity of the companies' domestic workers. It also aims to investigate the horizontal and vertical spillovers that might occur, formally or less formally, and to discover whether specialization and industrial competition play a role in facilitating knowledge spillover in Indonesia's manufacturing industry. What differentiates this study from previous similar studies is our investigation of whether or not the business orientation and intensity factors of domestic companies could be catalysts for knowledge spillover. To examine this, we use firm-level data and econometrics modelling to test our hypotheses. An important finding of this study is that the export orientation of domestic companies is a critical factor in promoting knowledge spillover.
\end{abstract}

\section{Keywords}

Foreign direct investment, technology transfer, knowledge spillover, manufacturing industry, Indonesia

\section{Introduction}

For recipients, foreign direct investment (FDI) is expected to provide long-term economic growth (Shahbaz \& Rahman, 2012) because it provides direct benefits through increased employment and capital, export opportunities and technology transfer (Blomstrom \& Koko 2002). For multinational corporations, technology transfer occurs not only in the form of hardware transfer but also in the forms of knowledge spillover, productivity spillover and rent spillover (Newman, Rand, Tabolt, \& Tarp, 2015), because of the direct and indirect interactions between domestic companies and foreign companies. The spillover effect of multinational corporations has long been a topic for debate. For example, Blomstrom (2014),

' Fakultas Ekonomi, Universitas Pasundan, Jl., Bandung, Indonesia.

\section{Corresponding author:}

Horas Djulius, Faculty of Economics and Business, Universitas Pasundan, Jl. Tamansari No. 6-8, Bandung 40II6, Indonesia.

E-mail: horasdjulius@unpas.ac.id 
Global Business Review I8(I)

among others, presents numerous discussions on this topic. Comparisons of performances of local and foreign companies, the productivity differences between them, the likelihood of spillover of efficiency, the nature of spillover and the market structures of the companies are among the topics that are given comprehensive coverage. Foreign direct investment can also provide indirect advantages through externalities (Sinani \& Klaus, 2002; Haskel, Sonia, \& Matthew, 2002) in the form of knowledge spillover (Atiken \& Harrison, 1999). For these reasons, many developing countries like Indonesia have attempted to attract FDI from more developed countries.

Technology transfer in the form of knowledge spillover can occur via foreign workers (Jacob \& Christopher, 2005) working in local companies. Transfers among workers might occur within the same industry or across different industries (Sjoholm, 1999). Meanwhile, competition between foreign and domestic companies could either promote knowledge spillover (Sinani \& Klaus, 2002) or discourage it (Newman, 2015). The extent of knowledge spillover could also be determined by the business orientation of local companies and the particular industry in which the local companies operate (Sinani \& Klaus, 2002).

In some cases, FDI can have a negative effect on the recipient countries. This can take the form of reverse spillover, whereby a foreign company increases its productivity as a result of its relationship with a local company (Wei \& Liu, 2003). Meanwhile, there may be no improvement in the local company's productivity; in other words, there is no transfer of technology, for various reasons (Long, Hale \& Miura 2014), even though the government of the recipient country has spent money or made other sacrifices to obtain the FDI.

Therefore, it is important to investigate whether the existence of FDI in Indonesia has resulted in technology transfer. If it has, it is important to then determine what types of spillover, particularly knowledge spillover, occurred in the manufacturing industry in Indonesia. This information will help the Indonesian government to formulate policies aimed at attracting FDI and policies governing the manufacturing industry. Furthermore, this study could also provide insights for the managers of local companies regarding the use of knowledge spillover that might occur through cooperation with foreign companies.

\section{Theoretical Framework}

The investment needs of every country, particularly developing countries, are satisfied not only by domestic savings but also by foreign capital. One of the assumptions frequently used in analyzing international economics is that capital is able to move freely in search of an appropriate return. This implies that capital should be able to move freely to every country (Feldstein, 1991). This foreign capital could be in the form of either FDI or foreign portfolio investment (FPI). It has long been assumed that the two are not related, or are interrelated only in the sense that they are either complementary or interchangeable (HumanickI et al., 2013).

One advantage that FDI has over FPI relates to the technology transfer that it embodies (Blomstrom, 2014; Sinani \& Klaus, 2002). This technology transfer is not only in the form of hardware (capital embodied) but also in the form of brain-ware and managerial skills of the local workers (labour embodied). These are the characteristics of FDI externalities in relation to technology transfer.

Externalities resulting from the existence of FDI in developing countries might take the forms of either knowledge spillover, productivity spillover or rent spillover (Newman et al., 2015). These externalities might be either formal or less formal (Driffield \& Love, 2007). An example of formal externalities involved a local company that became the partner of a foreign company (through FDI) by 
supplying necessary inputs or half-finished products. As a result of such formal interaction, a learning effect via technical assistance was expected, with a consequent improvement in the productivity of the domestic company's workers (Haskel et al., 2002). In addition to providing technical assistance, the foreign company could also impose high standards that the domestic company was forced to meet. This kind of interaction is called vertical linkage, which involves a relationship between a domestic company and a foreign company from different business sectors. This vertical linkage might take the form of either backward linkage or forward linkage. Backward linkage is a relationship whereby the foreign company is the recipient of the product and the domestic company is the supplier. Forward linkage is the reverse situation. Forward linkage seldom occurs in the case of developing countries such as Indonesia. Another type of formal externality is horizontal spillover. Horizontal spillover occurs between a foreign company and a domestic company (through FDI) in the same industry (or business sector) (Newman et al., 2015; Smarzynska, 2004), whereby they interact with each other in such a way that the domestic company is compelled to improve its productivity. Some researchers have questioned the existence of horizontal spillover (Newman et al., 2015) due to the real possibility that the foreign company will closely guard its technology to prevent competitors from copying it (Figure 1).

Externalities resulting from the presence of a foreign company (i.e., FDI) in a recipient country could also occur less formally. Less formal externalities are illustrated by interactions between a domestic company and the foreign company, such as informal contact, trade shows, supplier-distributor discussions, marketing agreements and exposure to partner products. (Rodriguez-Clare, 1996). Through these less formal ways, the presence of a foreign company can lead to productivity spillovers to domestic companies when they happen to be in the same region or the same business sector.

Knowledge spillover might also occur as a result of industry specialization or the level of competition in an industry (Sinani \& Klaus, 2002; Sjoholm, 1999; Wolfgang, 2001). A popular theory in relation to this kind of knowledge spillover is Marshall-Arrow-Romer (MAR) spillover. From this perspective, companies in a certain industry are able to utilize the technology and knowledge developed by other companies in the same industry that are located nearby. This exposure to technology and exchange of ideas facilitates further innovation and development within the industry. Two examples that are frequently used to explain this theory are the growth of the semiconductor industry in Silicon Valley and the film industry in Los Angeles, California. The concentration of the film industry in one area served to connect all the participants in the film production process, for example, producers, directors, screenwriters, animators and others, in a chain of production that enabled them to produce countless high-quality movies.

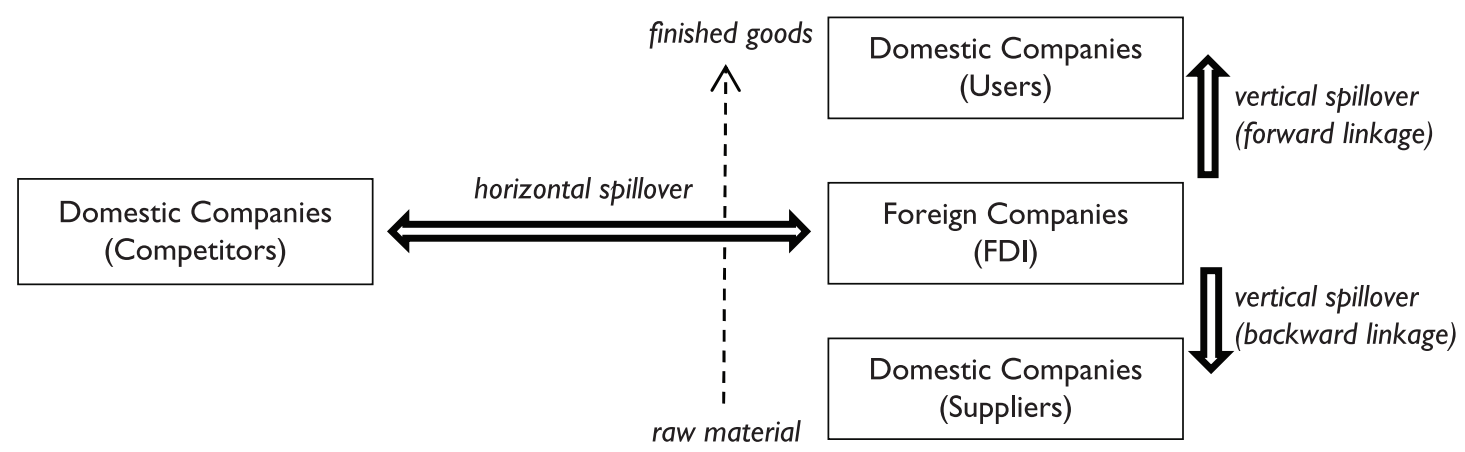

Figure I. Vertical and Horizontal Spillover

Source: Author's own. 
Other knowledge spillover theories are Porter spillover and Jacobs' spillover (Boja, 2012; Sjoholm, 1999). Porter spillover theory supports the view that competition among companies in a specialized industry that are located in close proximity can lead to the development and distribution of knowledge in the industry. Jacobs' spillover theory applies a similar approach to companies in different industries. Therefore, it can be seen that competition serves as a kind of catalyst for the industry specialization that produces knowledge spillover from foreign companies to domestic companies.

In this study, we also examined the effects of market (business) orientation and the intensity factor of the domestic company on knowledge spillover. In terms of market orientation, an export-oriented domestic company has the opportunity to interact with its foreign partner in ways that enable its workers' to improve their skills (Jacob \& Christopher, 2005). With regard to the intensity factor of domestic company, Amber Li and Zhu (2014) reported that the level of knowledge spillover for capital-intensive companies was higher than that for labour-intensive companies. The conceptual framework for this study is shown in Figure 2.

\section{Methodology}

The data we used were secondary data obtained from firms by the National Bureau of Statistics through annual surveys. We analyzed the unpublished data on these firms. Of the 153,512 companies that were surveyed, 24,591 were used as a sample for the study. This number was determined based on several criteria, as shown in Figure 3.

erated for 7 years commencing from 1996. This led to the identification of 14,229 companies (14,229 $\times 7$ years $=99,603$ firm years $)$. The second step was to eliminate companies with missing data or information (missing values). This reduced the sample to 5,088 companies $(5,088 \times 7$ years $=35,616$ firm years). The third step was to eliminate domestic companies that had received foreign funding for less than 5 years. The number of years over which companies had received funding depended on the companies' policies and also on government policies, which are generally set in 5-year time frames. The key criteria used to determine the number of years were the length of time for which the company had existed and the year when it was established. This meant that companies established after 1991 were excluded. This reduced the sample to $3,769(3,769 \times 7$ years $=26,383$ firm years $)$. The last step was to separate domestic and foreign firms. The basis for separation was the level of foreign capital investment, whereby firms with foreign capital investment of $\geq 20$ per cent were classified as foreign. This figure was chosen based on existing research, such as that conducted by Haskel et al. (2002) and Jacob and Christopher (2005), who notes that the International Monetary Fund limits companies to foreign capital investment of 10 per cent.

After applying the above criteria, it was found that the proportion of domestic companies was low, because a figure of 10-20 per cent is very low in terms of foreign capital investment in the case of Indonesia. The final sample included 3,513 domestic companies $(=3,513 \times 7$ years $=24,591$ firm years $)$.

In an attempt to find a solution to the research problem, a regression model based on panel data was used with estimation of generalized least squares. Stepwise regression was used to determine the robustness of the obtained coefficient of regression. The equation is as follows:

$$
\begin{aligned}
\operatorname{PROTI}_{i t}^{d}= & C_{6}+\lambda_{1} \cdot \mathrm{KAP}_{i t}^{d}+\lambda_{2} \cdot \mathrm{RAW}_{i t}^{d}+\lambda_{3} \cdot N_{-} \mathrm{TKI}_{i t}+\lambda_{4} \cdot N_{-} \mathrm{TKR}_{i t}+\lambda_{5} \cdot N_{-} \mathrm{HORI}_{i t} \\
& +\lambda_{6} \cdot N_{-} \mathrm{VERTI}_{i t}+\lambda_{7} \cdot R_{-} \mathrm{SPE}_{i t}+\lambda_{8} \cdot R_{-} \mathrm{COMP}_{i t}+\varepsilon_{6}
\end{aligned}
$$




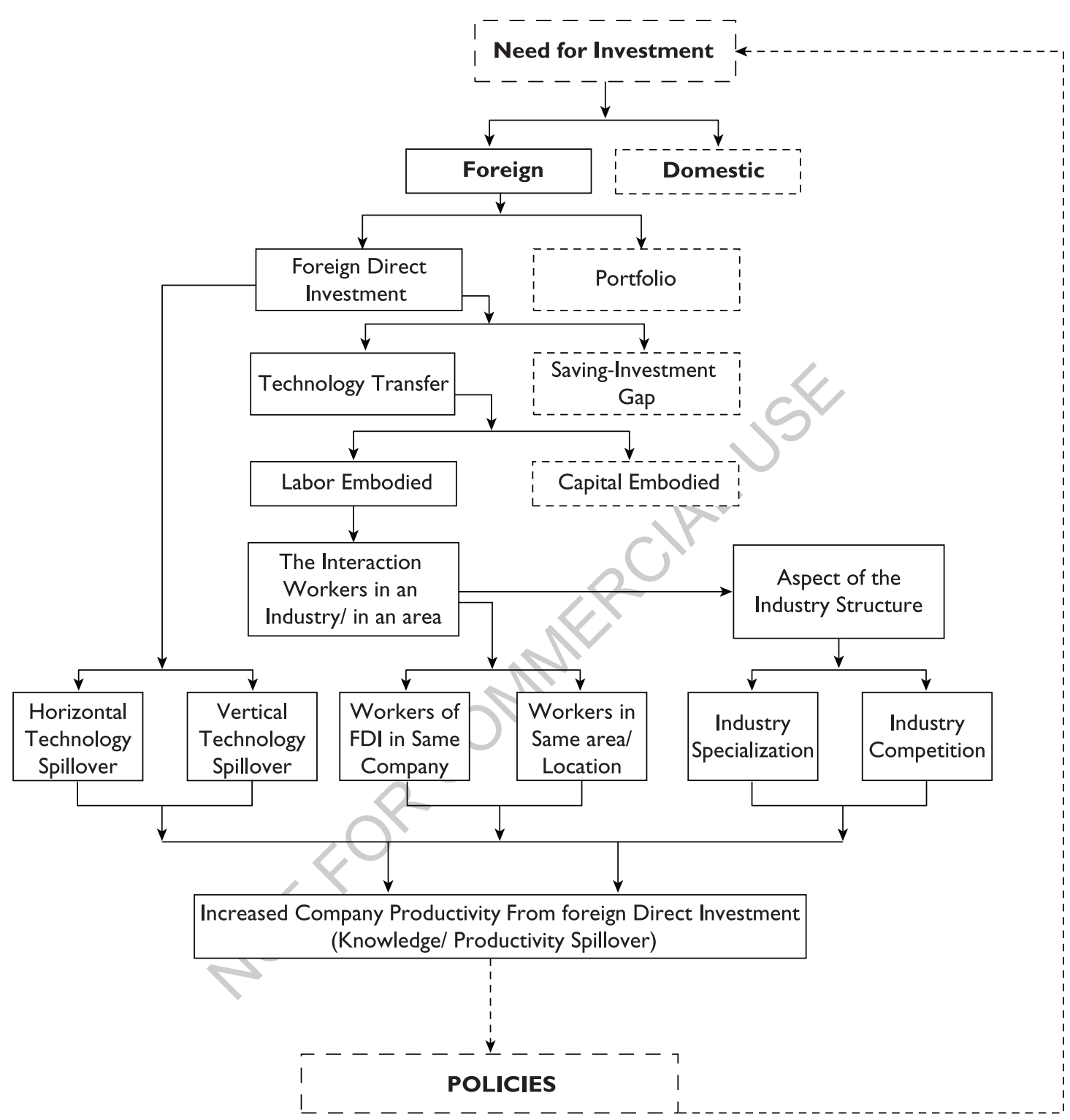

Figure 2. Conceptual Framework

Source: Author's own. 


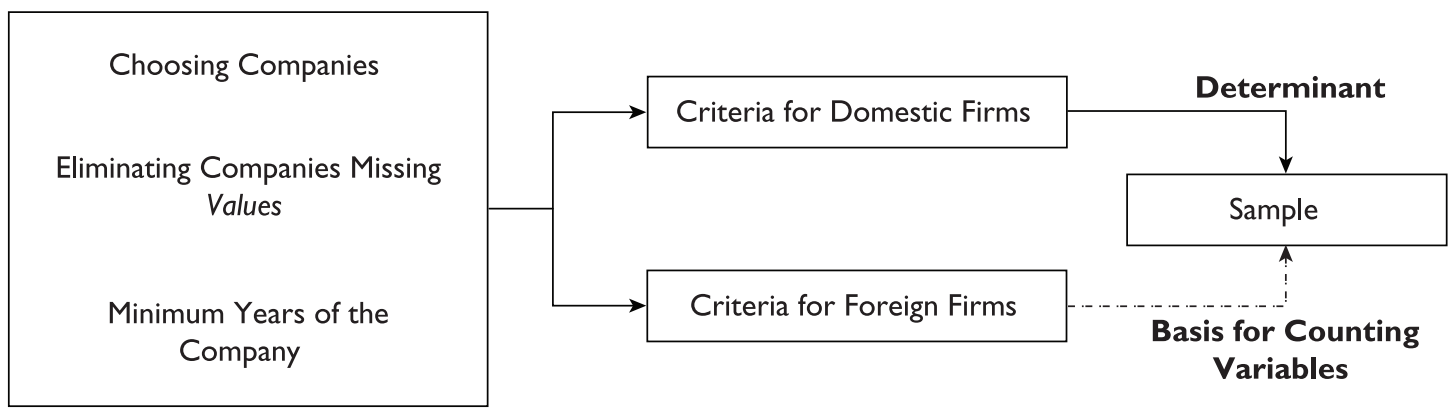

Figure 3. Flowchart Showing Sample Determination

Source: Author's own.

where

$i$

$t$

$\operatorname{PROTI}_{i t}^{d}$

$\mathrm{KAP}_{i t}^{d}$

$\mathrm{RAW}_{i t}^{d}$

N_TKI ${ }_{i t}$

$\mathrm{N}_{-} \mathrm{TKR}_{i t}$

$N_{-}$HORI $_{i t}$

$\mathrm{N}_{-}$VERTI $_{i t}$

$\mathrm{R} \_\mathrm{SPE}_{i t}$

$\mathrm{R} \_C O M P_{i t}$
$=$ company,

$=$ time frame (year),

$=$ company productivity, which is a proxy for the added value of each employee from a domestic company in a given year,

$=\quad$ capital value of a domestic company in a given year,

$=$ value of raw materials from a domestic company in a given year,

$=$ the number of workers in a company with foreign direct investment divided by the total number of workers within the same company; the value of the variable varies depending on the industry and time (year),

$=$ the number of workers in a company with foreign direct investment divided by the total number of workers in a given geographical location; the value of the variable varies depending on the region (province) and time (year),

the horizontal spillover, which is based on the weighted average of the contribution of foreign capital in every company; the value of this variable varies depending on the industry and time (year),

$=\quad$ the vertical spillover is based on the horizontal spillover together with the vertical relationship between industries, which is reflected in the inputs and outputs of the company; the value of this variable varies depending on the industry and time (year),

$=\quad$ specialization of the industry; the value of this variable varies depending on the region or area, industry and time (year) and

$=\quad$ the level of the industry's competition; the value of this variable varies depending on the location and time (year). 


\section{Results and Discussion}

\section{Clustered Industries}

\section{Clustered Based on $\Delta C / \Delta L$}

The first group was based on $\Delta \mathrm{C} / \Delta \mathrm{L}$ as proxy for the factor intensity used in every sector (ISIC 5-digit classification). Because the number of companies varied every year, the baseline was the number of companies in 1996 . The change in capital $(\Delta \mathrm{C})$ and change in labour $(\Delta \mathrm{L})$ were based on changes in these variables from 1996 to 1997 . Of the 22,997 companies that existed in 1996, there were 312 clustered industries based on ISIC 5-digit classification. The average $\Delta \mathrm{C} / \Delta \mathrm{Ls}$ of each company (with an identical unit of attributes in every company) were arranged from lowest to highest. This enabled the highest, medium and lowest values to be determined. According to Sudjana (1992), the division is as follows:

$$
\text { Position of } C_{i}=\text { data to } \frac{i(n+1)}{3} \text {, where } i=1,2, \ldots, n \text {, }
$$

with the following criteria:

$$
\begin{gathered}
\text { Average }(\Delta \mathrm{C} / \Delta \mathrm{L}) \leq C_{1} \text { is LOW }(\mathrm{L}) \\
C_{1}<\text { average }(\Delta \mathrm{C} / \Delta \mathrm{L}) \leq C_{2} \text { is MEDIUM }(\mathrm{M}) \\
\text { Average }(\Delta \mathrm{C} / \Delta \mathrm{L})>C_{2} \text { is } \operatorname{HIGH}(\mathrm{H}) .
\end{gathered}
$$

Using the above set of limitations, values of 26,672.13 and 256,780.5 were obtained for $C_{1}$ and $C_{2}$, respectively. The categorization of industries was made based on the value of $\Delta \mathrm{C} / \Delta \mathrm{L}$ for all sectors during 1996-2002. Of the 236 sectors chosen, 92 sectors were in the high $(\mathrm{H})$ cluster, 79 were in the medium (M) cluster, and 65 were in the low (L) cluster.

\section{Cluster Based on Export Percentages}

Similarly, values of 2.79 and 14.37 were obtained for $C_{1}$ and $C_{2}$, respectively, based on export percentages from all existing sectors during the period 1996-2002. Of the 236 sectors, 76 were in the H cluster, 93 were in the $\mathrm{M}$ cluster and 67 were in the L cluster.

To establish the different characteristics of the clusters, a Chow test was carried out to establish whether there were differences in the regression results (which explain the characteristics) between samples that were categorized based on the factor of intensity and/or orientation. The details presented below illustrate the $F$ statistic for each comparison made between the results of the regression on the overall data and sample data based on factor intensity among groups.

Chow Test for each cluster based on intensity factor

$$
\begin{aligned}
& A L L \\
& \mathrm{RSS}_{1}=\quad 9.34 \times 10^{20}(N=24,591)
\end{aligned}
$$




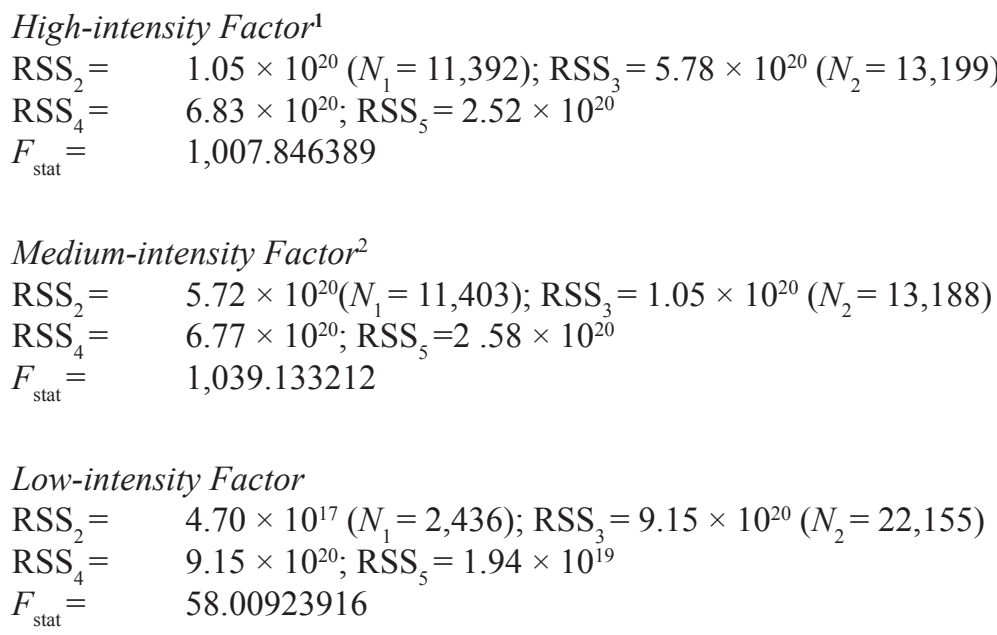

With such a high $F$ statistic result, the hypothesis that there is no difference between samples in general and the specific samples from each cluster is thus rejected. In other words, the sample distribution based on the intensity factor could be used in the subsequent analysis. Similarly, a test was conducted comparing the overall sample with group samples based on export orientation. The results of the Chow test are presented below:

Chow Test for each cluster of export orientation:

$A L L$

$\mathrm{RSS}_{1}=9.34 \mathrm{E}+20(N=24,591)$

High Exports ${ }^{3}$

$\mathrm{RSS}_{2}=9.72 \times 10^{18}\left(N_{1}=6,751\right) ; \mathrm{RSS}_{3}=1.10 \times 10^{20}\left(N_{2}=17,840\right)$

$\mathrm{RSS}_{4}=1.20 \times 10^{20} ; \mathrm{RSS}_{5}=8.15 \times 10^{20}$

$F^{\text {stat }}=18,606.06553$

Medium Exports

$\mathrm{RSS}_{2}=1.06 \times 10^{20}\left(N_{1}=7,138\right) ; \mathrm{RSS}_{3}=7.08 \times 10^{20}\left(N_{2}=17,453\right)$

$\mathrm{RSS}_{4}=8.15 \times 10^{20} ; \mathrm{RSS}_{5}=1.20 \times 10^{20}$

$F_{\text {stat }}=401.3339053$

Low Exports

$\mathrm{RSS}_{2}=3.14 \times 10^{20}\left(N_{1}=10,696\right) ; \mathrm{RSS}_{3}=1.20 \times 10^{20}\left(N_{2}=13,895\right)$

$\mathrm{RSS}_{4}=4.34 \times 10^{20} ; \mathrm{RSS}_{5}=5.00 \times 10^{20}$

$F_{\text {stat }}=3,145.919343$

These Chow tests showed that there were differences in characteristics in relation to the overall data based on both the group intensity factor and export orientation, thus the following section discusses the estimation of the research model for each sample. 


\section{Model Estimation Based on the Overall Data and Each Cluster}

In this study, three methods of data estimation were taken into consideration: the fixed-effect method, the random-effects method and the pooled model. However, because the cross section was bigger than the unit of time, the random-effects method was used instead of the fixed-effect method. To decide whether an estimation was to be conducted using the random-effects method or whether it was sufficient to use the pooled model (ordinary least square [OLS]), we used a Breusch-Pagan test with a Lagrangian multiplier. The results indicated that the equation should be estimated using the random-effects model (see the Appendix). The estimation results of the research model for the overall data and for each group using the random-effects model are presented in Table 1.

Table 1 presents a summary of the estimation results of equation (1) distributed based on the overall sample, while the sample was distributed based on intensity factor and export orientation. Each sample distribution based on intensity factor and export orientation was divided into three parts, that is, high, medium and low, so that there were seven estimation results for equation (1). The numbers provided were the regression coefficients for each independent variable for each sample classification, along with a $p$-value that indicated the probability of rejecting the null hypothesis that the variable had no significant influence. The adjusted $R^{2}$ values for the seven estimation results were relatively high, all of them being

Table I. Summary of the Results from the Estimation of the Overall Data and the Clustered Groupings

\begin{tabular}{|c|c|c|c|c|c|c|c|}
\hline Variable & $\begin{array}{c}\text { Overall } \\
\text { Sample of the } \\
\text { Data }\end{array}$ & $\begin{array}{l}\text { Sample of } \\
\text { High Intensity }\end{array}$ & $\begin{array}{l}\text { Sample of } \\
\text { the Medium } \\
\text { Intensity }\end{array}$ & $\begin{array}{l}\text { Sample of } \\
\text { the Low } \\
\text { Intensity }\end{array}$ & $\begin{array}{l}\text { Sample of } \\
\text { the High } \\
\text { Exports }\end{array}$ & $\begin{array}{l}\text { Sample } \\
\text { of the } \\
\text { Medium } \\
\text { Export }\end{array}$ & $\begin{array}{l}\text { Sample of } \\
\text { the Low } \\
\text { Exports }\end{array}$ \\
\hline KAP & 5178.33 & 1874.03 & 3224.907 & -271980 & $1553.2233^{*}$ & 33005.84 & 13839.09 \\
\hline$p$-value & $(0.49)$ & $(0.15$ & $(0.27)$ & $(0.38)$ & $(0.07)$ & & \\
\hline RAW & $3.96 * * *$ & $4.29 * * *$ & $6.870 * * *$ & $5.560 * * *$ & $4.84 * * *$ & 4.169*** & $14.27 * * *$ \\
\hline$p$-value & $(0.00)$ & $(0.00)$ & $(0.00)$ & $(0.00)$ & $(0.00)$ & $(0.00)$ & $(0.00)$ \\
\hline N_TKI & $-1.08 E+07$ & -5431602 & $-2.8 \mid E+07$ & 657415.5 & $3848752 *$ & $-2.12 E+07$ & $1.95 E+07$ \\
\hline$p$-value & $(0.59)$ & $(0.57)$ & $(0.35)$ & $(0.83)$ & $(0.09)$ & $(0.14)$ & $(0.37)$ \\
\hline N_TKR & 36084 I I & 8442224 & 4226927 & 1029183 & 3686 & 1.81 & $-1.35 E+07$ \\
\hline$p$-value & $(0.85)$ & $(0.33)$ & $(0.88)$ & $(0.75)$ & $(0.55)$ & $(0.10)$ & $(0.37)$ \\
\hline N_HORI & $2.00 \mathrm{E}+07 *$ & $1.22 E+07$ & $-3.03 E+07$ & 490364.6 & $8453266 * *$ & 3312080 & $-2.86 E+07$ \\
\hline p-value & & $(0.75)$ & $(0.12)$ & (0.8 & & & \\
\hline N_VERTI & 10173.25 & $4467405 * *$ & 7535.325 & 1308.146 & 33771.17 & 6839.412 & 1950869 \\
\hline$p$-value & $(0.90)$ & $(0.03)$ & $(0.97)$ & $(0.89)$ & $(0.50)$ & $(0.94)$ & $(0.59)$ \\
\hline R_SPE & $5824246 * * *$ & $2318584 * * *$ & 3066565 & -320486 & 205067 1*** & $|7| 257 \mid *$ & $2220309 * *$ \\
\hline$p$-value & $(0.00)$ & $(0.00)$ & $(0.13)$ & $(0.23)$ & $(0.00)$ & $(0.06)$ & $(0.03)$ \\
\hline R_COMP & 129695.3 & -27213.4 & -495871.5 & -93488.5 & $320722.2 * *$ & $1121662^{\text {**** }}$ & -1033396 \\
\hline & $(0.74)$ & $(0.91)$ & $(0.52)$ & $(0.22)$ & $(0.02)$ & & $(0.18)$ \\
\hline Adj $R^{2}$ & 0.6255 & 0.8866 & 0.6507 & 0.7164 & 0.9642 & 0.853 & 0.7476 \\
\hline Obs & 24591 & 10752 & 11392 & 2436 & 6751 & 7138 & 10696 \\
\hline
\end{tabular}

Source: Data Analysis Results.

Notes: (I) $* * * \alpha=1 \%, * * \alpha=5 \%$ and $* \alpha=10 \%$.

(2) The problems of collinearity and serial correlation were not found in the results of this estimation. Further, the potential heteroscedasticity problem was expected to decrease, as the generalized least squares method was used to estimate the model. 
greater than 60 per cent, and the value for the high export classification was 96.42 per cent. This indicated that all the independent variables were able to adequately explain the domestic companies' productivity.

The effects of each independent variable were as follows: (a) capital (KAP) only had a significant effect on the productivity of domestic companies in the high export category; (b) the raw material (RAW) variable had a significant influence on the productivity of domestic companies in all sample categories; (c) the variable numbers of workers in the company with FDI divided by the total number of workers in the same industry (N_TKI) only had a significant influence on the productivity of domestic companies in the high export category; (d) the variable numbers of workers in the company with FDI divided by the total number of workers in the same region (N_TKR) had a significant influence on the productivity of domestic companies in the overall sample and in the high export category; (e) the variable horizontal spillover (N_HORI) influenced the productivity of domestic companies in the overall sample and in the high export category; (f) the variable vertical spillover (N_VERTI) only influenced the productivity of domestic companies in the high factor intensity category; (g) the variable industry specialization (R_SPE) had a significant influence on domestic companies' productivity in almost all sample categories; and (viii) the variable industry competition level (R_COMP) only influenced domestic companies' productivity in the high and medium export categories.

\section{Transfer of Technology from Foreign Direct Investment Firms to Domestic Firms}

The variables N_TKI and N_TKR represented the hypothesis regarding the direct occurrence of knowledge spillover through labour turnover. N_TKI represented labour turnover in the same industry, while N_TKR represented labour turnover in the same region. The effects of these two variables on the productivity of local (domestic) companies were not robust. They only had influence over local companies that exported the majority of their production (export-oriented companies). This finding was consistent with that of Haskel et al. (2002), who suggested that a worker who had previously worked in a foreign company might transfer to a local company in the same industry. However, this contradicted the finding of Aitken and Harrison (1999) that foreign companies tend to carefully guard against the possibility of such labour turnover. With regard to exports, Sinani and Klaus (2002) noted that market or business orientation (towards either export or the domestic market) could be a channel for knowledge spillover. Sinani did not describe the relationship between FDI in a country and higher productivity of export-oriented local companies. Therefore, the present study is the first to explain such a relationship. In the Indonesian manufacturing industry, export-oriented local companies were able to employ workers who had worked for a foreign company. This was desirable because the local companies needed workers who had absorbed knowledge from the foreign company about how to deliver the production processes and product standards demanded by their foreign partners. The findings also indicated that labour turnover from foreign companies to domestic companies might occur in either the same sector (industry) or the same region. This meant that the skills of the foreign workers who transferred to a local company were not limited to skills that were directly related to the company's product (turnover in the same production/industry sector); they also included skills that were not directly related (turnover in the same region). Such indirect skills were related to the managerial skills of workers who had formerly been employed by foreign companies. These were skills that were needed by the local companies.

N_HORI was the variable that hypothesized the occurrence of horizontal spillover between similar or closely related companies, commonly known as intra-industry knowledge spillover. Newman et al. (2015) also hypothesized horizontal spillover occurrence, although his findings rejected the hypothesis. However, the results of our study contradict Newman's findings. In general, horizontal spillover did 
occur, particularly for export-oriented local companies. Knowledge spillover of this kind occurred due to competition between local companies and foreign companies. Therefore, the results of this study indicated that for export-oriented local companies, competition with foreign companies would facilitate knowledge spillover. This was possible because export-oriented local companies were able to pay workers, who had previously worked for foreign companies, the same salary they were receiving from the foreign companies. The key to this kind of knowledge spillover was the export or foreign business orientation.

N_VERTI was the variable that hypothesized the occurrence of vertical spillover among companies in different industries, commonly known as inter-industry knowledge spillover. Newman et al. (2015) and Sjoholm (1999) called this kind of knowledge spillover inter-sector spillover through the supply chain, while Sinani and Klaus (2002) called it backward and forward linkage with demonstration effects. Smarzynska (2004) called it horizontal spillover that indicated a relationship between a local company and a foreign company, that is, between the party that supplied half-finished products (upstream sector) and the party that used this supply to finish the products (downstream sector). In general, the current study did not find a pattern of vertical knowledge spillover among domestic companies in Indonesia. A particular exception was found in domestic companies with a high-intensity factor. Two assumptions were made when interpreting the findings. First, companies in the high-intensity factor category were capital-intensive companies. Second, FDI firms tended to be more capital-intensive than existing local companies. Therefore, it was understandable that vertical knowledge spillover existed between a local company supplying a half-finished product and a foreign company that used that product as an input (backward linkage). This is in line with the finding of Blalock and Gertler (2008). The findings of the current study also indicated that vertical knowledge spillover only occurred in capital-intensive local companies. Thus, it was important for local companies to meet the product standards set by foreign companies so that their products would be accepted. In this context, foreign companies indirectly provided knowledge to local companies on how to produce products to the desired standard. Transfer of knowledge occurred as a result of this relationship, both directly (via technical assistance) and indirectly (by specifying the desired product).

R_SPE was the variable that hypothesized the occurrence of knowledge spillover in local companies in highly specialized industries (with low levels of diversification). Sjoholm (1999) outlined how MAR spillover theory explained the relationship between the level of industry specialization and the level of competition with regard to knowledge spillover. According to this theory, industry specialization would lead to growth of the industry because knowledge flows would occur. Sjoholm (1999) reported that in Indonesia, high levels of diversification (the opposite of specialization) promoted industrial growth. The diversification mentioned by Sjoholm was at the national and district levels; at the provincial level, no relationship was found between industry diversification and industrial growth. Contrary to the findings of Sjoholm, this study found a positive relationship between the level of industry specialization and knowledge spillover at the provincial level. Thus, the findings of this study are consistent with MAR spillover theory. A high level of industry specialization was reflected in a policy of agglomeration in certain regions. Agglomeration involved the grouping (clustering) of several companies in a particular region to create a dedicated industrial area. Through agglomeration, the industrial efficiency of a region would increase because it would be easier for the company to obtain inputs, receive support in the production process and secure market accessibility. As a result of agglomeration, workforce supply from the education sector would be facilitated to produce a workforce with the skills needed by the industry. From the point of view of the workers, agglomeration allowed them to join companies and exchange experiences and knowledge through exhibitions and labour turnover. This was termed as MAR externality. This study found that the variable industry specialization significantly affected the increase in 
workforce productivity in local companies. This finding suggested that the significant effect of industry specialization on knowledge spillover occurred not only in the overall sample but also in companies with a high-intensity factor and export orientation. This was related to the previous finding that backward linkage between domestic and foreign companies should occur in the context of inter-company agglomeration. Domestic companies that did not have backward linkage with foreign companies could improve labour productivity by adopting export orientation in conjunction with agglomeration, which would ensure that the local companies were in a particular region where foreign companies were also active.

R_COMP was the variable that hypothesized the occurrence of knowledge spillover in highly competitive industries. Jacob and Christopher (2005) reported that a market structure of imperfect competition could facilitate knowledge spillover. Jones, Klinedienst and Rock (1998) stated that FDI could result in competition between foreign and local companies. Sinani and Klaus (2002) noted that the high level of competition experienced by a company could lower the company's performance (as measured by sales). The MAR spillover theory argued that a high level of competition might hinder industrial growth. Porter spillover theory and Jacobs' spillover theory (in Sjoholm, 1999) proposed a different argument to MAR. According to Porter, high levels of competition would promote industrial growth, while Jacobs stated that high levels of competition, accompanied by low levels of industry specialization, would trigger industrial growth. The present findings suggest that, in general, the level of competition did not affect the degree of knowledge spillover. However, an exception occurred for exportoriented domestic companies, where a high level of competition enabled them to absorb knowledge from foreign companies. Thus, a high level of competition made these domestic companies more efficient in terms of obtaining knowledge spillover.

Overall, almost all channels that might be used to achieve knowledge spillover existed in exportoriented domestic companies (with the exception of vertical spillover). Export-oriented domestic companies obtained knowledge spillover directly from FDI within the same sector (N_TKR), through relationships within the same industry (N_HORI) and by utilizing regional aspects of industry specialization (R_SPE) and industry competition (R_COMP). Therefore, export orientation was the key to knowledge transfer and technology transfer as a result of FDI in Indonesia.

\section{Conclusions and Practical Implications}

The application of FDI in Indonesia has served not only to complement the lack of capital necessary to grow the economy but also to enable technology transfer, particularly in the form of knowledge spillover. However, technology transfer did not emerge out of the blue; it was made possible by the existence of several factors and conditions. This study confirmed several findings reported by previous researchers and also discovered some new findings. Some of the important conclusions of this study are (a) horizontal spillover in the form of backward linkage was found for export-oriented domestic companies; (b) vertical spillover was found for domestic companies with a high-intensity factor; (c) a high level of industry specialization facilitates knowledge spillover; (d) a high level of competition could promote knowledge spillover for export-oriented domestic companies; and (e) export orientation by domestic companies could be a catalyst for various types of knowledge spillover from foreign companies to domestic companies.

These findings have significant implications, both directly and indirectly, for the managers of domestic companies in Indonesia. Managers must (a) be prepared to offer a competitive salary to workers who have worked for foreign companies, because these workers are able to bring technical and managerial skills to domestic companies; (b) utilize partnerships with foreign companies, particularly as the supplier 
of production components, because this could lead to technical assistance, which, in turn, could lead to knowledge transfer; (c) locate the company in close proximity to foreign companies or in an industrial cluster provided by the government; and (d) find and exploit export opportunities to obtain knowledge spillover from overseas business partners.

This study also has implications in terms of Indonesian government policies and regulations: first, policies to encourage and regulate industrial clustering in certain regions based on intra- and interindustry relationships; second, policies to encourage domestic industrial players to adopt export orientation and seek overseas business partners; and finally, the policies that continue to promote Indonesia as a potentially rewarding target for FDI.

\section{Acknowledgement}

The authors are grateful to the anonymous referees of the journal for their extremely useful suggestions to improve the quality of the article. Usual disclaimers apply.

\section{Appendix}

Breusch-PaganTest (LM) for the Estimation Method of Pooled Model

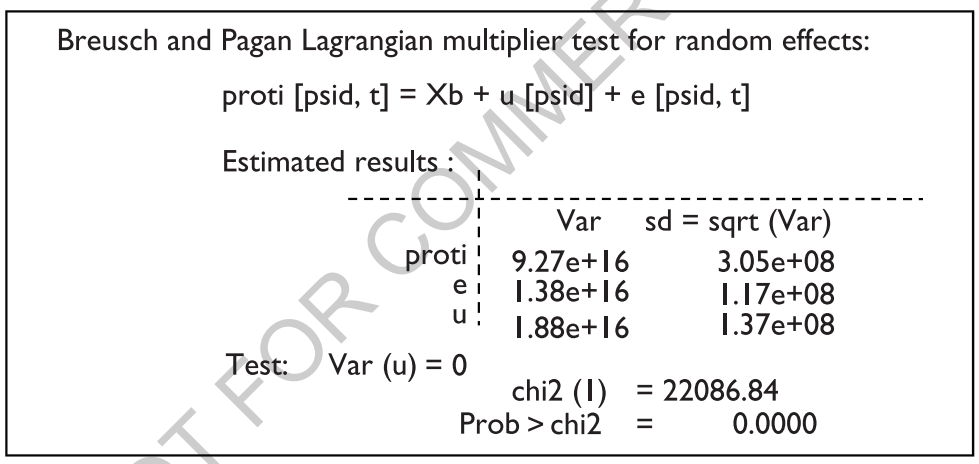

Source: Data Analysis Results.

\section{Notes}

1. The Chow test to test the different regressions between the two groups was conducted using the formula $F=\frac{S_{5} / k}{S_{4} /\left(N_{1}+N_{2}-2 k\right)}$. To test whether there were different regressions, and thereby to reveal any differences in characteristics between the high-intensity factor group and the overall group, a comparison of residual sum of squares (RSS) was conducted. $\mathrm{S}_{1}$ was the RSS from the regression on the group of non-high-intensity factor, $\mathrm{S}_{4}$ was the sum of $\mathrm{S}_{2}$ and $\mathrm{S}_{3}$, and $\mathrm{S}_{5}$ was the subtraction of $\mathrm{S}_{1}$ from $\mathrm{S}_{4}$. See Gujarati and Porter (2009) for further discussion.

2. The Chow test was repeated; $\mathrm{S}_{2}$ was the RSS of the regression on the medium-intensity factor group, $\mathrm{S}_{3}$ was the RSS from the regression on the non-medium-intensity factor group, $\mathrm{S}_{4}$ was the sum of $\mathrm{S}_{2}$ and $\mathrm{S}_{3}$, and $\mathrm{S}_{5}$ was the subtraction of $\mathrm{S}_{1}$ from $\mathrm{S}_{4}$.

3. This was similar to the previous Chow test; however, in this test, the grouping of the companies was based on their export percentage. 


\section{References}

Aitken, Brian J., \& Harrison, Ann E. (1999). Do domestic firms benefit from Foreign Direct Investment? Evidence from Venezuela. American Economic Review, 89(3), 605-618.

Amber Li, Yao \& Zhu, Linke. (2014). Sources of relatedness between industries and revealed comparative advantage: Evidence from China. Stockholm, Sweden: Stockholm School of Economics.

Blalock, Garrick, \& Gertler, Paul J. (2008). Welfare gains from Foreign Direct Investment through technology transfer to local suppliers. Journal of International Economics, 74(2008), 402-421.

Blomstrom, Magnus. (2014). Foreign investment and spillovers. New York: Routledge.

Blomstrom, Magnus, \& Kokko, Ari. (2002). FDI and human capital: A research agenda. Technical papers no. 195. Paris, France: OECD Development Centre.

Boja, Catalin. (2012). Analysis of knowledge spillovers in IT clusters. International Journal of Economic Practices and Theories, 2(4), 283-290.

Driffield, Nigel, \& Love, James H. (2007). Technology flows, outsourcing and productivity: An analysis of UK trade and FDI. Birmingham, UK: Economics and Strategy Group, Aston Business School, Aston University.

Feldstein, Martin. (1991). Domestic saving and international capital movements in the long run and the short run. Chapter in NBER book "International Volatility and Economic Growth: The First Ten Years of The International Seminar on Macroeconomics" (pp. 331-353). Amsterdam: Elsevier Science Publishers B.V.

Gujarati, Damodar N., \& Porter, Dawn C. (2009). Basic econometrics (5th ed.). New York: McGraw-Hill Irwin.

Haskel, Jonathan E., Sonia, C.P., \& Matthew, J.S. (2002). Does inward Foreign Direct Investment boost the productivity of domestic firms? National Bureau of Economic Research working paper 8724. Cambridge: National Bureau of Economic Research.

Humanicki, M., Robert, K., \& Krzysztof O. (2013). Foreign Direct Investment and Foreign Portfolio Investment in the contemporary globalized world: should they be still treated separately? Narodowy Bank Polsk Working Paper No. 167.

Jacob, Jojo \& Christopher, Meister. (2005). Productivity gains, technology spillover, and trade: Indonesian manufacturing, 1980-1996. Bulletin of Indonesian Economic Studies, 41(1), 37-56.

Jones, Derek C., Klinedienst, Mark, \& Rock, Charles. (1998). Productive efficiency during transition: Evidence from Bulgarian panel data. Journal of Comparative Economics, 26(3), 446-464.

Long, Cheryl Xiaoning, Galina Hale, Hirotaka Miura. (2014). Productivity Spillovers from FDI in the People's Republic of China. Asian Development Review, 31(2), 77-108.

Newman, Carol, Rand, J., Tabolt, T., \& Tarp, F. (2015). Technology transfers, foreign investment and productivity spillovers. European Economic Review, 76, 168-187.

Rodriguez-Clare, Andres. (1996). Multinationals, linkages, and economic development. American Economic Review, 86(4), 852-873.

Shahbaz, Muhammad, \& Rahman, Mohammad Mafizur. (2012). The dynamic of financial development, imports, Foreign Direct Investment and economic growth: Cointegration and causality analysis in Pakistan. Global Business Review, 13(2), 201-219.

Sinani, Evis \& Klaus, Meyer. (2002). Identifying spillovers of technology transfer from FDI: The case of Estonia. Copenhagen: Centre for East European Studies, Copenhagen Business School.

Sjoholm, Frederick. (1999). Productivity growth in Indonesia: The role of regional characteristics and direct foreign investment. Economic Development and Cultural Change, 47(3), 559-584.

Smarzynska, Beata. (2004). Does Foreign Direct Investment increase the productivity of domestic firms? In search of spillovers through backward linkages. The American Economic Review, 94(3), 605-627.

Sudjana. (1992) . Metode Statistika. 5th Edition. Bandung: Tarsito.

Wei, Yingqi, \& Liu, Xiaming. (2003). Mutual productivity spillovers between foreign and local firms in China. Aston Business School Research RP0307. Birmingham: Aston Business School Research.

Wolfgang, Keller. (2001). International technology diffusion. National Bureau of Economic Research working paper 8573. Cambridge: National Bureau of Economic Research. 